\title{
Introduction
}

\section{Educational Transitions - A Challenge to Research, Practice and Policy}

\author{
SVEND ERIK LARSEN
}

School of Communication and Culture, Department of Comparative Literature, Aarhus University, DK 8000 Aarhus C, Denmark. Email: litsel@cc.au.dk

In the wake of the Second World War, the demand for an expansion of higher education grew dramatically, first in Europe and the USA and later across the globe, and increasingly so in the twenty-first century. This situation changed the relation between the steps making up the ladder of the various national educational systems - in particular, from academically oriented secondary education to research-based higher education, a vital transition that confronts us with a plethora of open and pressing questions. The social developments that gained momentum from the 1950s onwards defined a new and vital role for research-based knowledge, targeting a broader range of sectors in society than before, not least in modern industrial and post-industrial welfare societies, a process that fostered an expansion of the area of research and education. The job market in the private and public sector required a labour force with skills based on education and training different from established thinking and practice, and with an understanding of the importance of innovation and life-long learning. The new demands for education and research opened the doors for a growing number of students, teachers and researchers with a more differentiated social background than was the case for previous generations. At the same time, educational policies had to be developed to transform, in an ongoing process, both secondary and higher education as well as the lower steps on the educational ladder, at times also requiring adding new steps.

This development has sparked a diversification of both secondary schools and institutions offering new types of four- to five- and two- to three-year post-secondary education beyond the programmes of classical universities, at times blending trainee periods and other elements typical for vocational education with academic education. New groups of students entered higher education with different skills, expectations and competencies compared with their predecessors, and universities had difficulties 
communicating to the institutions of secondary education precisely what they needed from them, and in some places alternative roads to higher education were opened. Each of the two levels became subject to ongoing and, more often than not, independent, reforms without sufficient attention to their interconnections, if any at all.

This situation created a conundrum that came to press hard on the educational system: on the one hand, the flexible adaptation of teaching programmes to the constantly changing societal needs generated a gap between secondary and higher education; on the other, the knowledge society required a smooth transition between the two educational levels to make the educational system cohere and to mobilize all the intellectual resources of our societies.

The Bologna agreement of 1999 established a systematic equivalence between higher education systems across Europe, while other types of tertiary or secondary education have not been subject to a similar initiative. Nonetheless, as the complexity of crossing vertically from one level to the next or horizontally between different types of education for the same age groups of students has increased in the growing international context of education, so has the complexity facilitating transitions between them. The report Eurydice Brief: Modernization of Higher Education in Europe: Access, Retention and Employability $(2015)^{1}$ discusses the issue as a oneway problem of 'access to higher education'; yet, any reflection of the necessary mutual exchange of knowledge and needs between the components for the entire system has been left out. The report only touches upon some of the unilateral transition problems, mostly comparing different legal, social and economic conditions for access. However, pedagogical and practical initiatives to bridge the gap between educational levels as well as a broader conceptual understanding of the function of progress within educational systems across the continent have not received sufficient attention, let alone the effect of broader social and cultural contexts.

With an initial focus on the transition between secondary and academic tertiary education, the discussions at the conference Mind the Gap. Bridging Secondary and Higher Education, held at the Wenner-Gren Foundation in Stockholm, 15-18 May 2019, showed convincingly that this issue involved more contexts than purely academic ones and a more comprehensive transfer of best pedagogical practices that transcended the narrowly academic sphere. The basic problem that united the invited speakers was: how to connect secondary with higher education in an expanding knowledge economy based on more diverse groups of students with different social and scholarly backgrounds in a landscape of more differentiated institutions of higher education. With the broad outlook adopted by the conference we included teachers from both systems and across disciplines, students crossing between them, researchers, administrators and policymakers. The fact that the speakers represented all those groups also broadened our discussions. It became clear that the basic opening question cannot be answered without taking into account the problem of transition in the European educational systems, vertically from primary schools up to

1. https://eacea.ec.europa.eu/national-policies/eurydice/content/eurydice-brief-modernisation-highereducation-europe-access-retention-and-employability_en (accessed 25 March 2020). 
higher education, horizontally between various types of tertiary education and the transfer between them, academic as well as vocational. Although the focus was on the European situation, the internationalization of education made it necessary also to draw inspiration from other parts of the world. Among the speakers, these other continents were represented and some of their papers have been selected for publication in this supplement.

In sum, the conference opened a panorama of perspectives across the entire educational spectrum beyond the initial scope of the conference. The transitions in the European educational systems represent a challenge shared by researchers, practitioners and policymakers, and the conference raised new research questions, addressing educational practices and educational policies across the continent. The chapters in this special supplement are selected and expanded papers from the conference, divided into three main research-oriented parts. Part 1 addresses the larger contexts (cognitive, political, media, social and assessment) which will have to be investigated jointly in order to enable us to define the limits and opportunities of educational transitions. Today, these are most often studied in isolation and never comprehensively. In Part 2 we bring a report from the city of Glasgow which shows how a local decision in a community to integrate various contexts and pedagogical dimensions in a comprehensive educational policy for all educational levels yields positive results. Part 3 offers insights into pedagogical experiments with a potential beyond their own disciplinary boundaries to facilitate transitions. The articles exemplify the four basic pedagogical dimensions of modern teaching practice: self-education, classroom, motivation and curriculum.

\section{Summary}

The conference made clear:

(1) that the problem of transitions between educational levels and sectors is broader than between secondary and higher research-based education and concerns the national educational systems in their entirety;

(2) that positive transition already in the primary school systems is crucial for successful transitions at the advanced levels;

(3) that educational transitions are a shared European problem that requires cross-European initiatives to be met with adequate reactions;

(4) that research on educational transitions is already going on, yet mostly with a national or local focus although with a potential for broader perspectives and collaborations.

This set of challenges calls for a combination of research activities with the aim of developing practices and policies that can strengthen European education on all levels. The following are required: 
- a survey of existing research on educational transitions with educational systems as a whole, and of the place of such research in existing European research programmes;

- a survey of the transitional mechanisms, practices and strategies across Europe;

- the creation of transversal initiatives across the individual systems and between them, including strategies and legal frameworks for the primary, lower and upper secondary and tertiary levels;

- initiatives to support the understanding of the importance of the basic cultural and social contexts for individual national systems, which define the conditions both for collaboration and for the transfer of best practices across cultural differences;

- the creation of mechanisms to strengthen recruitment to education and facilitate transition between lower and higher levels while reducing drop-out rates;

- the creation of a framework for a dialogue between agents on the different levels and in the different sectors of educational systems;

- research on pedagogical strategies, including the use of new media, to strengthen educational advancement, beyond the use of tests (PISA);

- an exploration of how successful transitions strengthen life-long learning across Europe and how the existing educational systems prepare citizens for engaging in this process;

- to gauge how successful systems of transition between all sectors and levels of education, leading to enhanced general as well as specialized levels of knowledge, skills and competencies, may bolster European society's resilience, productivity and spirit of innovation in an ever more competitive and globalized world.

It is our hope that this special supplement will inspire trans-European developments in research, practice and policy, realized in local and translocal environments, that will lead to a future improvement of access to and quality of education and knowledge production over the entire continent.

\section{Acknowledgements}

This supplement consists of selected and expanded articles from the conference Mind the Gap. Bridging Secondary and Higher Education, held on the premises of the Wenner-Gren Foundation in Stockholm, 15-18 May 2019. The event is one of a series of conferences on higher education in Europe, organized by the expert group HERCulES (Higher Education, Research and Culture in European Societies), formed by Academia Europaea in 2004 (www.info-ae.org). We are grateful for the ongoing collaboration with the Wenner-Gren Foundation (http://www. wennergren.org), which has hosted and sponsored this as well as previous HERCulES conferences. The main organizer of the conference was Svend Erik 
Larsen, supported by Peter Scott, Jan-Eric Gustafsson, Erik de Corte, Mikael Oliveberg and Britt-Marie Sjöberg from the Wenner-Gren Foundation, with assistance from Maria Helgöstam. Without the generous support from the Wenner-Gren Foundation neither the conference nor this supplement would have materialized. On behalf of the Academia Europaea and myself, I want to express my profound gratitude to the members of the organizing committee for a productive cooperation.

\section{About the Author}

Svend Erik Larsen, dr. phil., is Professor Emeritus of Comparative Literature, Aarhus University; Yangtze River Professor, Sichuan University (2016-2019); Honorary Professor, University College London 2014-2019, 2020-); Vice-President of the Board of Trustees of the Academia Europaea (2015-2019); Class Chair of Humanities, Academia Europaea (2014-2019); co-editor of Orbis Litterarum (2008-2020); board member of EuroScience (2018-); member of the task force on a white paper about Danish research policy, Ministry of Research and Development (1992-1993); external expert for the reform of the Danish upper secondary educational system; and member of exam committee, Ministry of Education (2003-2008). He has published on literary and cultural history, history of ideas, semiotics, memory studies, world literature. Among his books are Signs in Use (Routledge 2002, with J.D. Johansen), and Literature and the Experience of Globalization (Bloomsbury 2017). Among his edited volumes are Balzac (2000), Romanticism and Memory (2014), Literary Studies across Cultures (2018). He has published more than 400 articles in national and international journals and volumes. His current collective project is Landscapes of Realism, and his current book project is Forgiveness as a Cultural and Literary Challenge. 